\title{
Midwest Superconductivity Consortium
}

\author{
1991 Progress Report
}

\author{
G. L. Lied1, Acting Director \\ Purdue University \\ West Lafayette, IN 47907
}

\author{
January 1992 \\ for U.S. Department of Energy \\ Grant No. DE-FG02-90ER45427
}

\section{DISCLAIMER}

\begin{abstract}
This report was prepared as an account of work sponsored by an agency of the United States Government. Neither the United States Government nor any agency thereof, nor any of their employees, makes any warranty, express or implied, or assumes any legal liability or responsibility for the accuracy, completeness, or usefulness of any information, apparatus, product, or process disclosed, or represents that its use would not infringe privately owned rights. Reference herein to any specific commercial product, process, or service by trade name, trademark, manufacturer, or otherwise does not necessarily constitute or imply its endorsement, recommendation, or favoring by the United States Government or any agency thereof. The views and opinions of authors expressed herein do not necessarily state or reflect those of the United States Government or any agency thereof.
\end{abstract}
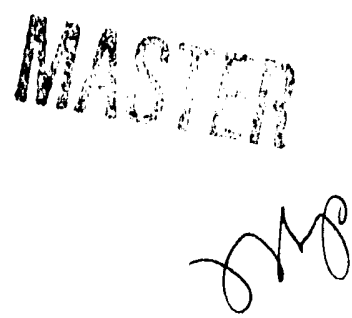
Table of Contents

Page

1. Abstract.................... 1

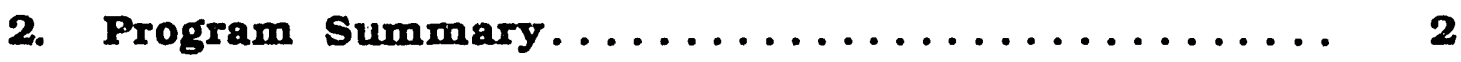

3. Research Program Thrusts................ 4

4. Selected Research Highlights............. 6

5. Talks and Presentations................. 12

6. Publications

In print.................... 18

Accepted for Publication................ 21

Submitted....................... 23

Appendix I - 1991 Cooperative Interactions.......... 25

Preprints and Reprints Enclosed (removed and cyced ryparatily) 


\begin{abstract}
The Midwest Superconductivity Consortium's, MISCON, mission is to advance the science and understanding of high $\mathrm{T}_{c}$ superconductivity. Programmatic research focuses upon key materials-related problems: synthesis and processing; and limiting features in transport phenomena. During the past year twenty-one projects produced over elghty-seven (87) talks and seventy-two (72) publications.

Key achievements this past year expand our understanding of processing phenomena relating to crystallization and texture, metal superconductor composites, and modulated microstructures. Further noteworthy accomplishments include calculations on 2-D superconductor insulator transition, prediction of flux line lattice meiting, and an expansion of our understanding and use of microwave phenomena as related to superconductors.
\end{abstract}




\section{PROGRAM SUMMARY}

The Midwest Superconductivity Consortium, MISCON, in the second year of operations has further developed its mission to advance the science and understanding of high $T_{C}$ superconducttvity. The goals of the organization were modified to reflect the current state of knowledge in the field and the unique capabilities of the institutions involved. An emphasis on group efforts was strengthened and the foundations for industrial involvement coupled with technology transfer were instituted. Activities of the participants during the past year illustrate an interactive and high level of performance.

The programmatic research continues to focus upon key' materials-related problems in two areas. The first area has a focus upon Synthesis and Processing while the second is centered around limiting features in Transport Properties of High $\mathrm{T}_{\mathbf{c}}$ Materials. The two areas involve twenty-one (21) research projects and thirty-three (33) senior participants. These participants have published forty-nine (49) papers and have submitted twenty-three (23) more in the past year. Further, the participants have given over eighty-seven (87) talks or conference presentations this past year.

Group activities and interactions with others were again a major strength of the operation. MISCON group meetings were held in January and August. A two day schedule for each meeting provided ample opportunity for the desired interactions to take place. Based upon these meetings the Program Committee revieured the goals and programmatic research. A revision of each was instituted to provide the framework for the new focus of the program. Coupled with the group meetings the participants were very active in cooperative interactions with other organizations. Among these activities were eleven (11) external speakers, twelve (12) collaborations on papers/abstracts, twelve (12) collaborations on facilities use, twenty (20) exchanges of samples and/or measurements, and four (4) gifts of equipment from industry.

To further enhance the group activitjes, some new programs were established. First, a new Information/Seminar Exchange was established to promote interaction within and between the groups. Second, a Programmatic Exchange was initiated to facilitate the use of special capabilities by all participants. Finally, a special capital equipment competition was held with group needs as the primary need requirement. Cost sharing was a key Issue and over $\$ 400 \mathrm{~K}$ worth of equipment was obtained with less than $\$ 200 \mathrm{~K}$ of MISCON funds. 
The formalization of the industrial program has been initiated. The extensive nature of the interactions made it important that a more formal structure be implemented. Primary reasons for inaugurating this program was to make all participants aware of these activities and to provide a mechanism for efficient flow of information to enable any technology transfer possible. 


\section{RESEARCH PROGRAM THRUSTS}

MIssion: The basic mission of the Consortium is to advance the science and understanding of high- $\mathrm{T}_{\mathrm{c}}$ superconductivity and to promote the development of new materials and improved processing technology for commercialization of superconductivity.

GOALS: The goals of the Consortium are:

(a) to develop, utilizing effective group efforts, the scientific and technological foundation for the industrial applications and commercialization of high-temperature superconductivity;

(b) to facilitate the transfer of technology from the Consortlum research laboratories into the industries of the Midwest; and

(c) to ensure that there is a continuing supply of engineers and scientists trained in this important field.

PROGRAMMATIC RESEARCH: To achieve some of the goals and in response to the mission of the Consortium, two general research programs have been defined. These two areas were selected from many possible ones to focus upon key materials-related problems where unique capabilities exist within the Consortium. Cooperative research programs in the following programmatic areas are supported. In addition, the Consortium encourages proposals for studies of new materials which can be expected to exhibit useful high-temperature superconductivity.

\section{Area 1: High-Temperature Superconducting Materials: Phase Relations, Reactions, Synthesis and Processing}

The development of high-temperature superconductors is contingent upon a thorough understanding of their material properties and of the processing variables to control these properties. Such properties include both thermodynamic and kinetic information about superconducting and normal-state phases. Processing variables encompass those necessary for the formulation of optimal synthesis and processing procedures to control the material properties. The Consortium supports investigation of these topics, as well as studies pertaining to the fabrication and characterization of 
high-temperature superconducting composites, multilayers, modulated structures, thin films, and other novel structures of potential usefulness.

\section{Area 2: Transport Properties of Bigh-Temperature Superconductors: Optimization of Critical Currents, Magnettc Screening, Dynamical Behavior and Other Limiting Factors}

Most proposed applications of high-temperature superconductors involve their ability to carry bulk supercurrents (e.g., wires, ribbons), to screen magnetic fields (e.g., enclosures, cavities), or to be components of electronic devices (e.g., sensors, rnagnetometers). All of these applications are contingent upon an understanding and control of transport properties. The Consortium supports research in this general area, Including studies of weak links (both artificially produced, and naturally occurring, as by defects, grain boundaries and textures); dynamics (flux lattice pinning, melting, and related phenomena); and interfacial transport (such as that between grains, films, contacts, substrates, and coatings). 


\section{SELECTED RESEARCH HUGHIGHTS}

The following are selected research accomplishments by MISCON participants in the past year. These achievements provide an insight into some of the new and exciting areas of research in progress by MISCON participants.

\section{Crystallization of High Temperature Superconducting Fulaments}

\section{A. I. Goldmon, D. K. Finnemore, and L. S. Chumbley}

Iowa State University

High temperature $\mathrm{x}$-ray studies of the melting of $\mathrm{Bi}_{2} \mathrm{Sr}_{2} \mathrm{Ca}_{1} \mathrm{Cu}_{2} \mathrm{O}_{8-\delta} / \mathrm{Ag}$ composites have been used to select precipitates that can be used as pinning centers for high performance conductors. The melting always takes place with the sequential formation 3 distinct solid phases in equilibrium with the liquid, $(\mathrm{Sr}, \mathrm{Ca})_{1} \mathrm{Cu}_{1} \mathrm{O}_{2}$. $(\mathrm{Sr}, \mathrm{Ca})_{2} \mathrm{Cu}_{1} \mathrm{O}_{3}$, and $(\mathrm{Sr}, \mathrm{Ca}) \mathrm{O}$. By controlling the temperature, the oxygen partial pressure, the dispersion of $\mathrm{Ag}$ and the amount of excess $\mathrm{Bl}$, the nucleation and growth rates of these phases. This is the first step in understanding the melt-texture processing of these composites for high performance magnet conductor.

\section{Crystallization of $\mathrm{REBa}_{2} \mathrm{Cu}_{3} \mathrm{O}_{7-x}$ High Temperature Superconducting Materlals from the Solidifled Melt}

R. W. McCallum, M. J. Kramer, L. S. Chumbley, and T. J. Folkerts

\section{Iowa State University}

Using a novel melt-spinning technique, we have been able to produce oxide glasses of $\mathrm{REBa}_{2} \mathrm{Cu}_{3} \mathrm{O}_{7-\mathrm{x}}(\mathrm{RE} 123)$ for $\mathrm{RE}=\mathrm{Nd}, \mathrm{Gd}$ when operating in a reduced oxygen partial pressure. By increasing the partial pressure of oxygen, the melt-spun material forms 5$10 \mathrm{~nm}$ grains of tetragonal RE123. The recrystallization of the amorphous glass has been studied using high temperature $x$-ray diffraction. The materials were found to recrystallize directly to the tetragonal $\mathrm{RE} 123$ structure upon heating to $700^{\circ} \mathrm{C}-800^{\circ} \mathrm{C}$ in oxygen. By controlling the nucleation from the amorphous state, we can better control the subsequent microstructure. Y123 has not been produced with an amorphous structure. These differences in microstructure have been modeled in terms of the liquidus temperature as a function of $\mathrm{RE}$ and oxygen partial pressure. This melt-spin technique produces samples with a more uniform dispersion of elements than can be obtalned with more conventional melt processing techniques. The highly disordered nature of these melt-spun materials should reduce and disperse secondary phases in the 
recrystallized RE123. This is an important step toward producing technologically useful bulk material with large critical currents.

Microstructural Dependence of Critical Current Density in Melt Textured $\mathrm{YBa}_{2} \mathrm{Cu}_{3} \mathrm{O}_{6+x}$ Superconductors

P. J. McGinn

University of Notre Dame

Additions of $\mathrm{BaSnO}_{3}$ to $\mathrm{YBCO}$ have been found to markedly improve the magnetization properties over similarly textured YBCO wires in low fields. Magnetic critical current densities $\left(\mathrm{J}_{\mathrm{C}}\right)$ in excess of $1.2 \times 10^{5} \mathrm{~A} / \mathrm{cm}^{2}$ in zero field, and $3.0 \times 10^{4} \mathrm{~A} / \mathrm{cm}^{2}$ at $1 \mathrm{~T}$ have been observed.

Annealing studies on textured YBCO wires indicate that high temperature annealing degrades the properties, including $J_{C}$ of the wires.

Study of Compositional Modulation in High-Temperature Superconductor Structures and Its Influence on Their Superconducting Properties

K. M. Choudhary and S. T. Ruggtero

University of Notre Dame

Epitaxial $\mathrm{Dy}_{1} \mathrm{Ba}_{2} \mathrm{Cu}_{3} \mathrm{O}_{7-\delta}(001)$ thin films showing $90 \mathrm{~K}$ critical transition temperature have been prepared by molecular beam depositton. $\mathrm{Dy}, \mathrm{BaF}_{2}$ and $\mathrm{Cu}$ in 1:2:3 ratio were coevaporated from effusion cells in presence of molecular oxygen. The epitaxy was achieved for the first time after post-annealing. The $\mathrm{Dy}_{1.3} \mathrm{Ba}_{1.7} \mathrm{Cu}_{3} \mathrm{O}_{7}$ $\delta(001)$ thin films show superconductivity at $53 \mathrm{~K}$. Epitaxial $\mathrm{NdMnO}_{3}(100)$ thin films have been prepared for the first time by molecular beam deposition and post-annealing. $\mathrm{NdMnO}_{3}$ has a perovskdte-type cubic unit cell (aO $=3.80 \AA$ ) and it is ideally suited for making $\mathrm{Dy}_{1} \mathrm{Ba}_{2} \mathrm{Cu}_{3} \mathrm{O}_{7-\delta}(001) / \mathrm{NdMnO}_{3}(100)$ superlattices.

High $T_{C}$ Superconducting Composites/Fums

\section{J. C. Garland}

The Ohto State University

We have developed a bulk superconducting composite material which combines the mechanical advantages of normal metals, 1.e., high thermal conductivity.

machinability and low normal state resistivity, with the superconducting properties of high $T_{c}$ oxdde superconductors. The composite is made by a powder metallurgy process in which a random matrix of silver metal is intermixed with a fused "skeleton" of yttrium barium copper oxide. Transport requirements have shown that the composite 
is superconducting at $90 \mathrm{~K}$ with as little as $16 \%$ volume fraction of superconductor.

Since the composite may be readily machined, we believe that it is perfectly suitable for applications which do not require very high critical densities.

We have developed a novel method of making proximity-effect (S-N-S) Josephson junctions which involves a single continuous layer of 5- $\mu \mathrm{m}$ wide YBCO film overlaying an approximately $1 \mu \mathrm{m}$ wide cross-strip of elther silver or gold. The presence of the metal layer at the junction disturbs the c-axds alignment of the overlaying YBCO film, and possibly the oxygen stoichtometry, resulting in a locally clepressed transition temperature. Typical junction critical currents are about $0.2 \mathrm{~mA}$ at $60 \mathrm{~K}$.

Normal Properties, Magnettsm, and Onset of Superconductivity in $\mathrm{La}_{1-x} \mathrm{Sr}_{x} \mathrm{NtO}_{4+\delta}$ and $\mathrm{La}_{2-x} \mathrm{Cu}_{y} \mathrm{Ni}_{1-y} \mathrm{Sr}_{x} \mathrm{NiO}_{4}$ Systems, and Real Space Pairing in High-T $T_{C}$ Systems

J. M. Honig

Purdue Untversity

We have recently attempted to improve the superconducting characteristics of $\mathrm{La}_{2} \mathrm{CuO}_{4+\delta} \delta$ and of $\mathrm{La}_{2-\mathrm{x}} \mathrm{Sr}_{\mathrm{X}} \mathrm{CuO}_{4}$ ceramics by fluorination. It was observed that the substitution of oxygen by fluorine was inhomogeneous; 1.e., most of the fluorine was concentrated in the surface layers. Nevertheless penetration into the bulk was also achieved, as documented by observed changes in lattice parameters. The effect was similar to that achleved by oxddizing the cuprate, thereby rendering $\mathrm{La}_{2} \mathrm{CuO}_{4}+\delta$ nonstoichiometric; the nonstoichiometric material then becomes superconducting. Simular results prevail when fluorination is carried out. Superconducting temperatures as high as $39 \mathrm{~K}$ have been encountered.

\section{Study of Naturally Modulated High $T_{C}$ Superconducting Compounds}

$$
\text { H. Sato }
$$

\section{Purdue University}

A new type of twin is found to extst in the $n=2$ type superconductors in the Bl-Sr-Ca-Cu-O system obtained by annealing from amorphous precursors. The twin plane is (015) if the period of the incommensurate modulation in the b-direction is disregarded. Because the structure has an incommensurate modulation in the bdirection with the period $b=5 b_{0}$, features of discommensuration are observed in the twin plane. High resolution, structural images with respect to fine structures of the boundary are successfully obtained. This is the first observation of twins in which detalled features of incommensurate structure are involved. 


\section{Quantum Effects in Quast-Two-Dimensional Superconductors}

\section{A. H. MacDonald and S. M. Girvin}

Indiana University

We have clarified the relationship between the superconducting mixed state and magnetic field strength. When the magnetic field is treated quantum-mechanically superconductivity can persist to arbitrarlly strong magnetic fields.

We have solved the microscopic mean-field equations for the vortex-lattice state in magnetic fields of arbitrary strength.

We have performed the first Monte Carlo calculation of the untversal conductivity at the two-dimensional superconductor-insulator transition in a model of interacting bosons which includes both disorder and long-range Coulomb interactions. We find that Coulomb interactions significantly change the universality class and yield $\left(\sigma^{*} \sim 0.8 \pm 0.3\right)(2 \mathrm{e})^{2} / h$ in reasonable agreement with current experimental estimates of the value in thin high- $T_{c}$ films.

Thermally Activated Flux Motion and Anisotropy in High-Temperature Superconductors

\section{J. R. Clem and V. G. Kogan}

\section{Iowa State University}

We have theoretically examined the meiting temperature of $T_{m}$ of the flux-line lattice in an anistropic superconductor and have predicted the dependence of $T_{m}$ upon the field orientation relative to the crystal. The prediction that the angular dependence is controlled in a simple way by the superconducting mass anisotropy has been verified experimentally in low-frequency torsional oscillator experiements performed in Professor David E. Farrell's group at Case Western Reserve University, Cleveland. A preprint describing this work ( $R$. G. Beck et al.) has been submitted to Physical Review Letters.

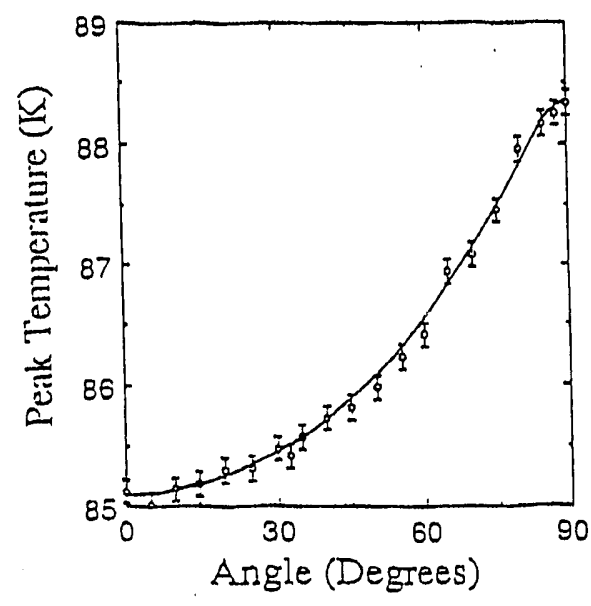

The graph shows the theoretical prediction (the solid curve) superimposed on the data points for $T_{m}$ versus the angle beween the external field $(2 \mathrm{~T})$ and the $\mathrm{c}$ axis of a twinfree $\mathrm{YBa}_{2} \mathrm{Cu}_{3} \mathrm{O}_{7-\delta} \delta$ single crystal. No adjustable parameters have been used in this plot. 
Microwave Disstpation in High Temperature Superconductors: Flux-Lattlce Dynamics,

Crystal Anisotropy, and Flux Ptnning

H. A. Blackstead

University of Notre Dame

Using a contact-less microwave technique, with an applied magnetic field varying to a maximum of $1.9 \mathrm{~T}$, we have observed flux-flow and phase-slip resistivity in a microsyntactically intergrown two phase $\mathrm{Pb}$ doped superconducting $\mathrm{Bl}-\mathrm{Sr}-\mathrm{Ca}-\mathrm{Cu}-\mathrm{O}$ of nominal composition $\mathrm{Bi}_{1.6} \mathrm{~Pb}_{0.4} \mathrm{Sr}_{17} \mathrm{Ca}_{2} \mathrm{Cu}_{3} \mathrm{O}_{\mathrm{x}}$. The onset temperature for the high temperature phase is $106.5 \mathrm{~K}$, while the lower temperature phase manifests itself at $71 \mathrm{~K}$. Flux-flow is observed superimposed on an isotropic background phase-slip resistivity, and is locally maximal several degrees below each transition temperature. Flux-flow resistivity, a consequence of the Lorentz force on a fluxoid, varies as $\sin ^{2}(\phi)$, where $\phi$ is the angle between the applied magnetic field and the if current. The fit to the experimental data, was achieved with relatively small error, even though the sample was polycrystalline. The measurements revealed the relative concentrations of the two phases.

Far Infrared and Microwave Magneto-Disstpation in High $T_{C}$ Superconductors

\section{W. J. Tomasch and J. K. Furdyna}

University of Notre Dame

We have developed a leaderless nondestructive microwave technique for evaluating high temperature superconductors. The method utllizes the transmission and reflection of $\mathrm{mm}$ microwaves and ylelds both the surface resistance and surface reactance.

Microwave reflection and transmission measurements have been employed to demonstrate magneto-reflection and magneto-transmission effects in a 1800 angstrom thick YBCO(123) film.

Comparisons of our microwave data with predictions of a recent theory, developed by MISCON scientists at Iowa State University (Mark W. Coffey and John R. Clem), are expected to yield valuable quantitative information regarding flux pinning at microwave frequencies in high temperature superconductors.

Our microwave and far-infrared transmission data $(\mathrm{H}=0)$ both suggest the occurrence of paraconductivity (fluctuation superconductivity) for approxdmately five degrees kelvin above the transition temperature. 
Measurement of the Bernoulli Potential in $\mathrm{Y}_{1} \mathrm{Ba}_{2} \mathrm{Cu}_{3} \mathrm{O}_{7-\delta}$ and $\mathrm{Y}_{1} \mathrm{Ba}_{2} \mathrm{Cu}_{4} \mathrm{O}_{x}$ Fums Thomas R. Lemberger

The Ohio State University

We measured the Bernoulli voltage $V_{B}$ and kinetic inductance $L_{k}$ for the same high quality $\mathrm{YBa}_{2} \mathrm{Cu}_{3} \mathrm{O}_{7-\delta} \mathrm{fulm}$. The film has a critical current density $\mathrm{J}_{\mathrm{C}}$ more than $2 \mathrm{x}$ $10^{6} \mathrm{~A} / \mathrm{cm}^{2}$ at $4.2 \mathrm{~K}$ with the sample dimension, $w \times d \times l=90 \mu \mathrm{m} \times 1000 \AA \times 17 \mathrm{~cm}$.

The measurement of $\mathrm{V}_{\mathrm{B}}$ shows the reproducibllity of our previous measurement of $V_{B}$, even with a different counter-electrode geometry: the sign of $V_{B}$ is positive, and $V_{B}$ is about $5 \mathrm{nV}$ at $\mathrm{J}=10^{6} \mathrm{~A} / \mathrm{cm}^{2}$ and $\mathrm{T}=4.2 \mathrm{~K}$. Previously $\mathrm{V}_{\mathrm{B}}$ was about $6 \mathrm{nV}$ with positive sign.

Neutron Diffraction and Defect Studies of High $T_{C}$ Superconductors

W. B. Yelon and J. W. Farmer

University of Missouri-Columbia

Verification of the high quality of the single crystals of $\mathrm{YBa}_{2} \mathrm{Cu}_{3} \mathrm{O}_{7}$ grown at MURR $\left(300,000 \mathrm{~A} / \mathrm{cm}^{2}\right.$ critical current at 4000 Oe at $\left.30 \mathrm{~K}\right)$ was completed.

The effect of $\mathrm{Zn}, \mathrm{Ni}, \mathrm{GA}$ and mixed doping on the structure of $\mathrm{YBa}_{2} \mathrm{Cu}_{3} \mathrm{O}_{7}$ has been determined by neutron diffraction and will be correlated to the changes in electrical properties $\left(T_{C}, J_{C}\right.$, etc.).

Intrinsic and Induced Weak Link Behavior in $\mathrm{YBa}_{2} \mathrm{Cu}_{3} \mathrm{O}_{7-\delta}$ FUlms

M. W. McElfresh and R. G. Retfenberger

Purdue University

YBCO epitaxial thin films with superconducting transition temperatures as high as $92 \mathrm{~K}$ are being routinely produced in our Pulsed Lase- Deposition (PLD) system.

Samples on bicrystal boundaries and on substrates with ion-milled step edges, in order to produce isolated grain boundary superconducting weak links, are being prepared in. collaboration with Steve Riıggiero of Notre Dame University and James Garland of Ohio State University.

We have shown that the topography of YBCO thin films can account for the extraordinary critical current densities $\left(>10^{7} \mathrm{~A} / \mathrm{cm}^{2}\right)$ routinely observed in these materials. Screw dislocations are effective pinning sites at low magnetic fields $(<0.25$ kOe) while the weaker pinning at surface growth steps can still give large pinning strengths up to very high fields. 


\section{TALKS and PRESENTATIONS}

1. "Superconductivity in Very Strong Magnetic Fields", A. H. MacDonald, University of British Columbia, December 4, 1991.

2. "Untversal Conductivity of Dirty Bosons in Two Dimensions", S. M. Girvin. March APS Meeting, Indianapolis, IN, March, 1992.

3. "Universal Conducttvity at the Superconductor-Insulator Transition in Two Diniensions", S. M. Girvin, Nobel 90th Jubllee Symposium, Goteborg, Sweden, December 5, 1991.

4. "Universal Conductivity at the Superconductor-Insulator Transition in Two Dimensions", S. M. Girvin, Midwest Solid State Theory Symposium, E. Lansing, MI, October 7, 1991.

5. "Universal Conductivity at the Superconductor-Insulator Transition in Two Dimensions", S. M. Girvin, 1991 Yukawa Int. Seminar on Low-Dimensional Field Theorles and Condensed Matter Physics, Kyoto, Japan, July 31, 1991.

6. "Universal Conductivity at the Superconductor-Insulator Transition in Two Dimensions", S. M. Girvin. Winter School on "Anyons, Fractional Statistics and 2D Magnetism," ICCMP, Brasilia., Brazil, July 8-19, 1991.

7. "Universal Conducttvity at the Superconductor Insulator Transition in Two Dimensions", S. M. Girvin, Gordon Research Conf., Brew ster Academy, Wolfeboro, $\mathrm{NH}$, June 12, 1991.

8. "Universal Conductivity at the Superconductor-Insulator Transition in Two Dimensional Films", s. M. Girvin, Argonne National Lab, Argonne, IL, May 7, 1991.

9. "Universal Conductivity at the Superconductor-Insulator Transition in Two Dimensional Fllms", S. M. Girvin, NORDITA, Copenhagen, Denmark, May 17. 1991.

10. "Universal Conductivity of Dirty Bosons", M. Wallin, S. M. Girvin, E. S. Sorensen, and A. Peter Young, March APS Meeting, Indianapolis, IN, March, 1992.

11. "Universal Properties of the Superconductor to Insulator Transition in 2D Charged Boson Films", E. S. Sorensen, A. P. Young, M. Wallin, and S. M. Girvin, March APS Meeting, Indianapolis, IN, March, 1992.

12. "Universal Conductivity of 2D Films at the Field-Tuned SuperconductorInsulator Transition", M. Cha, M. Wallin, and S. M. Girvin, March APS Meeting, Indianapolis, IN, March, 1992.

13. "Vortex Lattices in Superconducting Films", D. P. Arovas, K. Mullen, S. M. Girvin and A. H. MacDonald, March APS Meeting, Indianapolis, IN, March, 1992.

14. "Critical Currents for Vortex Depinning in the Present of Line and Point Defects", D. Stroud, K. H. Lee, and S. M. Girvin, March APS Meeting, Indianapolis, IN, March, 1992.

15. "Exact Mean Fleld Solutions for Flux Lattice States", M. R. Norman, H. Akera, A. H. MacDonald, March APS Meeting, Indianapolls, IN, March, 1992. 
16. "Universal Properties of the 2D Superconductor-Insulator Transition", S.M. Girvin, Brown Untversity, Nov. 15, 1991.

17. "Quantum fluctuations in 2D Superconductors", S.M. Girvin. Condensed Matter Physics Gordon Conference, Brewster Academy, June 13, 1991.

18. "Universal Conductivity at the 2D Superconductor-Insulator Critical Point", MinChul Cha (MacDonald, Giroin Group)
a) Ohio State Untversity, Feb. 1991.
b) University of Illinois, Urbana-Champaign, Feb. 1991.
c) University of Minnesota, Feb. 1991.
d) Boston University, March, 1991.

19. "Flux Lattice States at High Magnetic Fields", (given by our collaborator, M.R. Norman) at the Physics at High Magnetic Fields Conference, Florida State University, May 1991.

20. "Future Applications of Superconductivity", D.K. Finnemore, Student Awards Dinner Talk, Luther College, 23 April 1991.

21. "Melting and Freezing of Bi-Sr-Ca-Cu-0 Compo"inds", D.K. Finnemore, 6th International Workshop on Critical Currents, Cambridge University, UK, July 11 , 1991.

22. "Critical Flelds in High Temperature Superconductors", D.K. Finnemore, Advanced Studies Symposium, Los Alamos National Laboratory, August 22, 1991.

23. "Flux Pinning and Critical Currents in Superconductor-Normal Metal Composites", D.K. Finnemore, Tokal University 4th International Conference on Superconductivity, Tokai University, Honolulu, Hawall, October 10, 1991.

24. "Sirain Tolerant Superconductors", D.K. Finnemore, The Metallurgical Society (TMS) Spring Meeting, New Orleans, Feb. 19, 1991.

25. "Ideas and Applications of Superconductivity", D.K. Finnemore, Seminar, Carieton College, April 5, 1991.

26. "The Structure of Glassy Bi(2212)", J. Hammonds, Argonne National Laboratory, Jan. 1991.

27. "2D Pancake Vortices and Josephson Strings", J. R. Clem, IBM Thomas J. Watson Research Center, Yorktown Heights, New York, April 15, 1991.

28. "General Theories of the Magnetic Responses of Crystalline and Granular Superconductors", J. R. Clem, International Workshop on Magnetic Susceptibility of Superconductors and Other Spin Systems, Coolfont, Berkeley Springs, West Virginia, May 21, 1991.

29. "Fundamentals of Vortices in the High-Temperature Superconductors", J. R. Clem, Allied-Signal, Torrance, California, August 9, 1991.

30. "Magnetic Properties of the High-Temperature Superconductors", J. R. Clem. NATO Adranced Study Institute on Physics and Materials Science of HighTemperature Superconductors II, Porto Carras, Neos Marmaras, Halkidikd, Greece, August 20, 1991. 
31. "Magnetic Fleld Dependence of ac Permeabllity and if Surface Impedance in TypeII Superconductors", J. R. Clem, Physics Seminar, University of Neuchatel, Neuchatel, Switzerland, October 14, 1991.

32. "Phenomenology of Conventional and High- $\mathrm{T}_{\mathrm{c}}$ Superconductors: An Overview". J. R. Clem, Fifteenth Gwatt Workshop, Gwatt, Switzerland, Octoher 17, 1991.

33. "A Survey of Some Recent Experimental and Theoretical Results on Critical Currents in the High-Temperature Superconductors", J. R. Clem, Electric Power Research Institute, Palo Alto, Callfornia, October 29, 1991.

34. "Phenomenological Theories of the Anisotropic Vortex Structure in HighTemperature Superconductors", J. R. Clem, Materials Research Soclety Fall 1991 Meeting, Boston, Massachusetts, December 2, 1991.

35. "Phenomenology of the Electrodynamic Properties of the High-Temperature Superconductors: Anisotropy, Intragranular Properties, and Intergranular WeakLink Effects ", J. R. Clem, Conference on High-T $\mathrm{C}$ Superconductivity (three lectures), International Centre of Condensed Matter Physics, Untversidade de Brasilla, Brazil, December 5 and 6, 1991.

36. "Two-Dimensional Pancake Vortices, Josephson Strings, and Their Roles in the High-Temperature Superconductors", J. R. Clem, Concensed Matter Physics Seminar, Indiana University, Bloomington, Indiana, December 13, 1991.

37. 'Vortices in Layered Superconductors with Josephson Coupling", V. G. Kogan, Conference on Superconductivity with Applications, Now York Staice Institute on Superconductivity, Buffalo, New York, September 24-26, 1991.

38. "Vortices and Flux-Line Lattices in Anisotropic Superconductors", V. G. Kogan, Untversity of California, San Diego, CA, December 18, 1991.

39. 'Line Energles of Josephson Strings Connecting 2D Pancake Vortices in a Josephson-Coupled-Layer Model of Highly Anisotropic High-Temperature Superconductors", J. R. Clem, American Physical Society March Meeting, Cincinnat1, OH, March 20, 1991.

40. "Reversible Magnetization and Torques in Anisotropic High-k Type-II Superconductors", Z. Hao and J. R. Clem, American Physical Society March Meeting, Cincinnati, Ohio, March 22, 1991.

41. "Magnetic Properties of a $\mathrm{Bi}_{2} \mathrm{Sr}_{2} \mathrm{CaCu}_{2} \mathrm{O}_{8}$ Single Crystal Below TC", J. H. Cho, $\mathbf{Z}$. Hao, D. C. Johnston, and J. R. Clem, American Physical Society March Meeting, Cincinnati, Ohio, March 22, 1991.

42. "Flux-Line Lattices of Highly Anisotropic Superconductors in Small Fields", L. J. Campbell, L. Daemen, and V. G. Kogan, American Physical Society March Meeting, Cincinnati, Ohio, March 22, 1991.

43. "A Scaling Property in the Reversible Magnetization of Anisotropic High-k TypeII Superconductors,", Z. Hao and J. R. Clem, Materials and Mechanisms of Superconductivity - High-Temperature Si:perconductivity III, Kanazawa, Japan, July 25, 1991.

44. "Radio Frequency Surface Impedance of Type-II Superconductors: Dependence Upon The Magnitude and Angle of an Applied Static Magnetic Fleld", J. R. Clem and $M$. W. Coffey, Materials and Mechanisms of Superconductivity - HighTemperature Superconductivity III, Kanazawa, Japan, July 25, 1991. 
45. "Line Energies of Josephson Strings Connecting 2D Pancake Vortices in a Josephson-Coupled-Layer Model of Highly Anisotropic High-Temperature Superconductors", John R. Clem. March Meeting of the Americar Physical Soclety, Cincinnati, OH, March 20, 1991, Bull. Am. Phys. Soc., 36, 775 (1991).

46. "Recrystallization of Rapidly Quenched and $\mathrm{Bi}_{2} \mathrm{Sr}_{2} \mathrm{CaCu}_{2} \mathrm{O}_{\mathrm{x}}$ ", R.W. McCallum, presented at the Spring MRS Meeting in Anaheim, CA, May 2, 1991.

47. "Grain Boundaries in Highly Textured Ceramic Superconductors Crystallized from an Amorphous Precursor", R.W. McCallum, presented at the Spring MRS Meeting in Anaheim, CA, May 2, 1991.

48. "Flux Creep and Pinning Potential in Zone Melted YBa2 $\mathrm{Cu}_{3} \mathrm{O}_{\mathrm{X}}$ ", D. Shi, K. Goretta, J. Chen, S. Salem-Sugui, P. McGinn, W. Chen, and N. Zhu, TMS Annual Meeting, New Orleans, LA, February 1991.

49. "Zone Melt Texturing of $\mathrm{YBa}_{2} \mathrm{Cu}_{3} \mathrm{O}_{6+\mathrm{x}}$ and Related Compounds", P. McGinn, Purdue Undversity, March 12, 1991.

50. "Textured Microstructures in $\mathrm{YBa}_{2} \mathrm{Cu}_{3} \mathrm{O}_{6+\mathrm{x}}$ and Related Compounds by Zone Melting", P. McGinn, W. Chen, N. Zhu, L. Tan, and S. Sengupta, American Ceramic society Annual Meeting, Cincinnati. OH, Ajpril 1991.

51. "Effect of $\mathrm{Y}_{2} \mathrm{BaCuO}_{5}$ Phase Additions on the Magnetic Properties of $\mathrm{YBa}_{2} \mathrm{Cu}_{3} \mathrm{O}_{6}+\mathrm{X}$ Textured Wires", P. J. McGinn, S. Sengupta, N. Zhu, W. Chen, and L. Tan, American Ceramic Society Annual Meeting, Cincinnati, OH, April 1991.

52. "Annealing Effects on the Critical Current Density of Zone Melt Textured YBa $2 \mathrm{Cu}_{3} \mathrm{O}_{6}+\mathrm{x}^{\prime \prime}$, W. Chen, P. J. McGinn, S. Sengupta, N. Zhu, and L. Tan, American Ceramic Soclety Annual Meeting, Cincinnati, OH, April 1991.

53. "Microstructure Effects in Zone Melt Textured $\mathrm{YBa}_{2} \mathrm{Cu}_{3} \mathrm{O}_{6}+\mathrm{x}$ with $\mathrm{Y}_{2} \mathrm{BaCuO}_{5}$ and $\mathrm{BaSnO}_{3}$ Additions", P. McGinn, C. Varanasi, D. Balkin, W. Chen, and N. Zhiu, Ceramic Superconductors Symposium, Electronics/Glass and Optical Materials Meeting of the American Ceramic Society, Arlington, VA, October 1991.

54. "Microstructure Effects in Zone Melt Textured $\mathrm{YBa}_{2} \mathrm{Cu}_{3} \mathrm{O}_{6}+\mathrm{x}$ with $\mathrm{Y}_{2} \mathrm{BaCuO}_{5}$ and $\mathrm{BaSnO}_{3}$ Additions", P. McGinn, C. Varanasi, D. Balkin, W. Chen, and N. Zhu, TMS Fall Meeting, Cincinnati, OH, October 1991.

55. "Effects of $\mathrm{BaSnO}_{3}$ Additions on Zone Melt Textured $\mathrm{YBa}_{2} \mathrm{Cu}_{3} \mathrm{O}_{6}+\mathrm{x}$ ", P. J. McGinn, D. Balkin, C. Varanasi, and M. Black, 1991 MRS Meeting, Boston, MA, 1991.

56. "Microstructure and Transport Properties of Zone Melt Textured $\mathrm{YBa}_{2} \mathrm{Cu}_{3} \mathrm{O}_{6+\mathrm{x}}$ and Related Compounds", P. McGinn, W. Chen, N. Zhu, Purdue University MISCON Group Meeting, Jan. 1991.

57. "Zone Melt Texturing of $\mathrm{YBa}_{2} \mathrm{Cu}_{3} \mathrm{O}_{\mathrm{y}+\mathrm{x}}$ with 211 Additions", P. McGinn, W. Chen, N. Zhu, TMS Annual Meeting, New Orleans, LA, Feb. 1991.

58. "Flux Creep and Pinning Potential Distribution in Zone Melted YBa2 $\mathrm{Cu}_{3} \mathrm{O}_{6}+\mathrm{x}$ ". D. Shi, K. Goretta, J. Chen, S. Salem-Sugui, P. McGinn, W. Chen, N. Zhu, TMS Annual Meeting, New Orleans, LA, Feb. 1991.

59. "Determination of Sign of Charge Carrier from Bernoulli Effect in Superconductors", J.Y. Lee and T.R. Lemberger, APS 1991 March Meeting. 
60. "Fluctuation Conductivity in Model Granular Superconductors in Zero and Strong Magnetic Fields: Glassy Behavior", Z.Q. Wang and D. Stroud, Bull. Am. Phys. Soc., 36, 517 (1991).

61. "I-V Characteristics near the Vortex Glass Transition in Weakly Coupled Granular Superconductors", K.H. Lee and D. Stroud, Bull. Am. Phys. Soc., 36, 936 (1991).

62. "The Physics of Superconducting Arrays", D. Stroud, General Colloquium at Northeastern University, Jan. 31, 1991.

63. "The Physics of Disordered Superconductors",D. Stroud, Adriatico Research Conference on Inhomogeneous Media, Trieste, Italy, June 11-14, 1991.

64. "Normal Magnetic and Superconducting Properties of $\mathrm{La}_{2}-\mathrm{Sr}_{\mathrm{x}} \mathrm{NiO}_{4}+\mathrm{y}$ and $\mathrm{La}_{2-\mathrm{x}} \mathrm{Sr}_{\mathrm{x}} \mathrm{Cu}_{1-\mathrm{yNl} \mathrm{N}_{4}}$ Systems and Real Space Pairings in High $\mathrm{T}_{\mathrm{C}}$ Systems", J.M. Honig and J. Spalek, MISCON Group Meeting, Purdue Untversity, W. Lafayette, IN, Jan. 18, 1991.

65. "Sr Doping Study of the Mid-Infrared Band and a-b Plane Phonons in Single Crystais of La2NiO4". Xlang-Xin B1, P.C. Eklund, E. McRae, J.G. Zhang, Ying Wang, P. Metcalf, J. Spalek, and J.M. Honig, Am. Ceram.Soc. Mtg., Cincinnat, Ohio, April 30, 1991.

66. "Reversible and Irreversible Magnetic Properties of High Temperature Superconductors", M. McElfresh, National Institute of Science and Technology. Boulder, CO; March 1991.

67. "Studying Magnetic Properties with a Squid Magnetometer", M. McElfresh, Florida State University, Tallahassee, FL; June 1991.

68. "Correlation of Surface Topography and Flux Pinning in Superconducting YBaCuO Films", M. McElfresh, Los Alamos National Laboratory, Los Alamos, NM, September 1991 .

69. "Reversible and Irreversible Magnetic Properties of High Temperature Superconductors", M. McElfresh, Carnegle-Mellon University, Pittsburgh, PA, November 1991.

70. "New Directions with High $T_{C}$ Superconductors", M. McElfresh, presented at International Society for Hybrdd Microelectronics Meeting, Lafayette, IN, May 1991.

71. "Reversible and Irreversible Properties of High $\mathrm{T}_{\mathrm{C}}$ Superconductors", $\mathbf{M}$. McElfresh

Science 11.1 Seminar, February 1991

Matertals Chemistry Seminar, February 1991

Solid State Physics Seminar, March 1991

72. "Important Considerations for Magnetic Measurements", M. McElfresh, Florida State University, Tallahassee, FL, May 1991

73. "Reversible and Irreversible Magnetic Behavior of YBaCuO Single Crystals", M. McElfresh, National Instit. of Standards \& Tech., Boulder, CO, March 1991

74. "Study of Naturally Modulated High $\mathrm{T}_{\mathrm{C}}$ Superconducting Compounds",H. Sato. MISCON Group Meeting, Jan. 18, 1991, W. Lafayette, IN. 
75. "Structural Developments in the Bl-Sr-Ca-Cu-O Superconductors from Amorphous Precursors", H. Sato. W. Zhu, T. Ishiguro and N. Ohnishi, Feb. 18, 1991, TMS, New Orleans, LA.

76. "Growth of $\mathrm{Dy}_{1} \mathrm{Ba}_{2} \mathrm{Cu}_{3} \mathrm{O}_{7-\delta}(001)$ and $\mathrm{Dy}_{1+\mathrm{x}} \mathrm{Ba}_{2-\mathrm{x}} \mathrm{Cu}_{3} \mathrm{O}_{6}$ (001) High-Temperature Superconductor Thin Films by Molecular Beam Epitaxy", Krishna M. Choudhary, to be presented at the SC GLOBAL 92 - Fifth Annual International Superconductor Applications Convention, January 29-31, 1992, San Diego, CA.

77. "Landau Quantization and Superconductivity at High Magnetic Fields", M.R. Norman, H. Akera and A.H. MacDonald, invited talk "Physical Phenomena at High Magnetic Fields", Florida State University, May 15-18, 1991

78. "Synthesis of $\mathrm{YBa}_{2} \mathrm{Cu}_{3} \mathrm{O}_{7-\delta}$ Films from Metallo-Organic Precursors", C. Venkatraman, G.L. Lledl, A.I. Schindler, TMS - March 1992 in San Diego, CA.

79. "The Materials Science of YBCO Superconductors", D. V. Baxter, Seminar on Solid-State Chemistry/Solid-State Physics, Indiana University, December 17, 1991.

80. "Electrical Transport Properties of Silver/High $T_{C}$ Superconductor Composites", J.J. Calabrese, S.E. Hebboul and J.C. Garland, Am. Phys. Soc. Mtg., March 18-22, 1991.

81. "Fabrication of High $T_{C}$ Proximity Coupled Josephson Junctions", S.T. Herbert, X. Jiang and J.C. Garland, Am. Phys. Soc. Mtg., March 18-22, 1991.

82. "Measurement of Novel High-T Proximity Coupled Josephson Junctions", S. T. Herbert, D. C. Harris, S. E. Hebboul, and J. C. Garland, submitted for the 1991 March Meeting of the Am. Phys. Soc.

83. "Transport Properties of Electron-Doped Sm2-x $\mathrm{Se}_{\mathrm{X}} \mathrm{CuO}_{4-\mathrm{y}}$ Superconductors", Y. M. Wan, J. J. Calabrese, S. E. Hebboul, J. C. Garland, E. A. Early, Y. Dalichaouch, M. C. DeAndrade, R. F. Jardim, and M. B. Maple, submitted for the 1992 March Meeting of the Am. Phys. Soc.

84. "Microwave Dissipation in Crystalline BSCCO and YBCO", H. A. Blackstead, D. B. Pulling, P. J. McGinn, and J. Z. Liu, Bull Am. Phys. Soc. 35, No. 3, 716 (1991).

85. "Magnetic Resonance in Gd123", D. B. Pulling, H. A. Blackstead, C. A. Clough, and P. C. W. Chu, Bull Am. Phys. Soc. 35, No. 3, 716 (1991).

86. "Lattice Parameter Changes in Neutron Irradiated $\mathrm{YBa}_{2} \mathrm{Cu}_{3} \mathrm{O}_{7}$ ", X. Ding and J. W: Farmer, March 1991 American Physical Society Meeting.

87. "Structural, Transport, and Magnetic Properties of $\mathrm{Bi}_{2} \mathrm{Sr}_{2}-\mathrm{xLa}_{\mathrm{x}} \mathrm{CuO} \mathrm{y}$, J. Diederichs, J. S. Schilling, A. Schlogl, J. J. Neumeier, C. Allgeier and W. B. Yelon, March 1991 American Physical Society Meeting. 


\section{PUBLICATIONS - IN PRINT}

(Copies are appended to this report)

1. "Universal Conductivity of Two-Dimensional Films at the SuperconductorInsulator Transition", M. Cha, M. P. A. Fisher, S. M. Girvin, M. Wallin, and A. P. Young, Phys. Rev. B 44, 6883 (1991).

2. 'Vortex-lattice States at Strong Magnetic Flelds", H. Akera, A.H. MacDonald, S.M. Girvin and M.R. Norman, Phys. Rev. Lett. 67, 2375 (1991).

3. "Lower Critical Field of a Josephson-Coupled Layer Model of High- $T_{C}$ Superconductors", J. R. Clem, M. W. Coffey, and Z. Hao, Phys. Rev. B 44, 2732-2738 (1991).

4. "Vortex Inertial Mass for a Discrete Type-II Superconductors", M. W. Coffey and J. R. Clem, Phys. Rev. B 44, 6903-6908 (1991).

5. The Vortex Lattice of Highly Antsotropic Layered Superconductors in Strong, Parallel Magnetic Flelds", L. Bulaevskil and J. R. Clem, Phys. Rev. B 44, 1023410238 (1991).

6. "Unified Theory of Effects of Vortex Pinning and Flux Creep upon the if Surface Impedance of Type-II Superconductors", Mark W. Coffey and John R. Clem, Phys. Rev. Lett. 67, 3, 386-389 (1991).

7. "In-situ X-ray Investigation of the Melting of Bi-Sr-Ca-Cu-O Phases", J. Polonka, Ming Xu, Qlang Li, A. I. Goldman, and D. K. Finnemore, Appl. Phys. Lett. Dec. 30 Issue.

8. "Experimental Observations of Electronic Structures for Ternary Metallic Glasses of $\left(\mathrm{Cu}_{1-\mathrm{x}} \mathrm{Ni}_{\mathrm{X}}\right) 33 \mathrm{Zr}_{67}$ ", Ming Xu and Z.X. Zhao, Phys. Rev. B. 44, No. 17, 9652-9655 (1991) (Goldman, Finnemore, Chumbley Group)

9. "Calculations of Remanent Magnetization for Hard Superconductors in Various Critical State Models", Ming Xu, Phys. Rev. B, 44, 2713 (1991). (Goldman, Finnemore, Chumbley Group)

10. "Crystallization of $\mathrm{Bi}_{2} \mathrm{Sr}_{2} \mathrm{Ca}_{1} \mathrm{Cu}_{2} \mathrm{O}_{8}$ Superconducting Filaments Produced by Gas Jet Fiberzation", K.R. Jacobs, T.A. Miller, D.K. Finnemore and A.I. Goldman, IEEE Trans. Magn. MAG, 27, 917 (1991).

11. "Environmental Contamination of Amorphous Bi-Sr-Ca-Cu-O Fibers", K.R. Jacobs, T.A. Miller, A.I. Goldman, D.K. Finnemore, R.A. Gleixner, J. Right and D: Zeigler, J. Superconductivity 4, No. 4, 311-313 (1991).

12. "Melt-Spin Processing of $\mathrm{YBa}_{2} \mathrm{Cu}_{3} \mathrm{O}_{7-\mathrm{x}}$ ", T.J. Folkerts, M.J. Kramer, K.W. Dennis, and R.W. McCallum, J. Mat. Res., 6, No. 10, Oct. 1991.

13. "Flux-Flow and Phase-Slip Dissipation in Crystalline $\mathrm{Bi}_{2} \mathrm{Sr}_{2} \mathrm{CaCu}_{2} \mathrm{O}_{8}+\delta$ and $\mathrm{YBa}_{2} \mathrm{Cu}_{3} \mathrm{O}_{8}-\delta "$, H.A. Blackstead, D. B. Pulling, P. J. McGinn and J. Z. Liu, Physica C 174, 394-400 (1991).

14. "Flux-Flow and Phase-Slip Dissipation in Crystalline $\mathrm{Bi}_{2} \mathrm{Sr}_{2} \mathrm{CaCu}_{2} \mathrm{O}_{8}+\delta$ and $\mathrm{YBa}_{2} \mathrm{Cu}_{3} \mathrm{O}_{8}-\delta^{\prime \prime}$, H.A. Blackstead, D.B. Pulling, and C.A. Clough, Phys. Rev. B, 44. No. 13, p. 6955-6960 (1991). 
15. "Magnetically Induced Microwave Surface Resistance of Superconducting $\mathrm{Bi}_{2} \mathrm{Sr}_{2} \mathrm{CaCu}_{2} \mathrm{O}_{8-\mathrm{x}}$ Crystals", E.K. Moser, w. J. Tomasch, H.A. Blackstead, D.B. Pulling, and J.Z. Liu, Bull. Am. Phys. Soc. 36, 710 (1991).

16. "Microwave Magneto-Dissipation in Crystalline $\mathrm{YBa}_{2} \mathrm{Cu}_{3} \mathrm{O}_{6+\mathrm{x}}$ and $\mathrm{Bi}_{2} \mathrm{Sr}_{2} \mathrm{CaCu}_{2} \mathrm{Og} "$, E.K. Moser, W.J. Tomasch, P.J. McGinn and J.Z. Liu, Physica C 175, 235-241 (1991).

17. "Twin-Boundary Pinning and Flux-Flow in Zone-Melt-Textured $\mathrm{YBa}_{2} \mathrm{Cu}_{3} \mathrm{O}_{7-\delta}$ Crystals", H.A. Blackstead, D.B. Pulling, P.J. McGinn, and W.H. Chen, J. Superconductivity 4, No. 4, 263-269 (1991).

18. "Flux-Flow in Sintered Polycrystalline $\mathrm{YBa}_{2} \mathrm{Cu}_{3} \mathrm{O}_{7-\delta} \delta$, H.A. Blackstead, D.B. Pulling, P.J. McGinn and C.A. Clough, Physica C 176, 534-538 (1991).

19. "Current Activated Residual Surface Resistance in High Temperature Superconductors ", H. A. Blackstead, Solid State Communications 80, No. 6, 401-404 (1991).

20. "Phase-Slip Dissipation in Crystalline La $1.8 \mathrm{Sr}_{0.2} \mathrm{NiO}_{4}+\delta$ ", H.A. Blackstead, D.B. Pulling, J. Spalek, and J.M. Honig. Solld State Comm. 80, No. 6, 405-409 (1991).

21. "Microstructure and Magnetic Properties of Zone Melt Textured $\mathrm{YBa}_{2} \mathrm{Cu}_{3} \mathrm{O}_{6+\mathrm{x}}$ with $\mathrm{BaSnO}_{3}$ Additions", P. McGinn, N. Zhu, W. Chen, C. Varanasi, L. Tan, D. Balkin, Physica C, 183, 51-56 (1991).

22. "Microstructure and Critical Current Density of Zone Melt Textured $\mathrm{YBa}_{2} \mathrm{Cu}_{3} \mathrm{O}_{6+\mathrm{x}} / \mathrm{Y}_{2} \mathrm{BaCuO}_{5}$ with $\mathrm{BaSnO}_{3}$ Additions", P. McGinn, W. Chen, N. Zhu, T. Li, C. Varanasi, S. Sengupta, Appl. Phys. Lett. 59, p. 120-122, 1991.

23. "Flux Creep and Pinning Potential Distribution in Zone Melted $\mathrm{YBa}_{2} \mathrm{Cu}_{3} \mathrm{O}_{\mathrm{X}}$ ", D. Shi, K. Goretta, S. Salem-Sugui, P. McGinn, W. Chen, N. Zhu, Appl. Phys. Lett. 69, July, 1991.

24. "Microstructure and Critical Current Density of Zone Melt Textured $\mathrm{YBa}_{2} \mathrm{Cu}_{3} \mathrm{O}_{6+\mathrm{x}}$ with $\mathrm{Y}_{2} \mathrm{BaCuO}_{5}$ Additions", P. McGinn, W. Chen, N. Zhu, S. Sengupta, T. Ld, Proceedings of 1991 TMS Symposium on High Temperature Superconductivity, Physica C 176, 203-208 (1991).

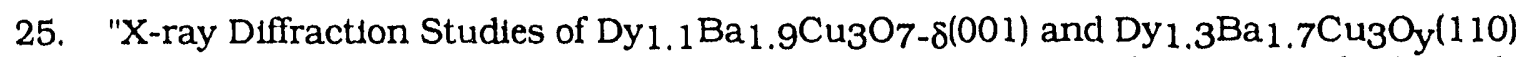
High Temperature Superconductor Thin Film", K.M. Choudhary, P. Seshadri and J. Bae, (accepted, Phys. Rev. B).

26. "The Effect of Strong Flux Line Correlations on the Irreversibility Line of High Temperature Superconductors", J.C. Garland, C.C. Almasan, and M.B Maple), Physica C 181, 381-384, (1991).

27. "Radio Frequency Spectral Response of Two-Dimensional Josephson Junction Arrays", S.E. Hebboul and J.C. Garland, Phys. Rev. B, 43, No. 13, 13703-13706, (1991).

28. "Electrical Transport Properttes of Silver/High-T Superconductor Composites", J. J. Calabrese, S. E. Hebboul, and J. C. Garland, Bull. Am. Phys. Soc. 36, 727 (1991)

29. "Fabrication of High-T $\mathrm{C}$ Proxdmity Coupled Josephson Junctions", S. T. Herbert. X. Jiang and J. C. Garland. Bull. Am. Phys. Soc. 36, 879 (1991). 
30. "Dynamics of Granular Superconductors at Zero and Large Magnetic Fields: Glassy Behavior", Z. Q. Wang and D. Stroud, Phys. Rev. B 44, 9643 (1991).

31. "IV Charactertstics of a Model Vortex Glass: A Numerical Study", K. H. Lee and D. Stroud, Phys. Rev. B 44, 9780 (1991).

32. "Excitation Spectrum of a Superconducting Sphere in a Superconducting Host: Effects of Phase Fluctuations", P.M. Hul and D. Stroud, Phys. Rev. B Vol. 43, No. 7, 6139-6142, (1991).

33. "Structural Changes of $\mathrm{Bi}_{1.8} \mathrm{Sr}_{2}\left(\mathrm{Ca}_{1-\mathrm{x}} \mathrm{Y}_{\mathrm{X}}\right) \mathrm{Cu}_{2.2} \mathrm{O}_{\mathrm{Z}}$ Ceramics with Yttrium Content Studied by Electron Diffraction and High-Resolution Electron Microscopy".

Takashi Onozuka, Yoshihiro Iwabuchi, Tetsuo Fukase, Hiroshi Sato and Terence E. Mitchell, Physical Review B, Condensed Matter, Vol. 43, No. 16-A, 1 June 1991. 


\title{
PUBLICATIONS - ACCEPTED FOR PUBLICATION
}

\author{
(Preprints are appended to this report)
}

1. "Universal Conductivity at the Superconductor-Insulator Transition In TwoDimensions", S. M. Girvin, M. Wallin, M. Cha, M. P. A. Fisher, and A. P. Young, Prog. Theoretical Physics (in press).

2. "Model for the Low-Temperature Transport of Bl-based High-Temperature Superconducting Tapes", L. N. Bulaevskdi, J. R. Clem, L. I. Glazman, and A. P. Malozemoff, Phys. Rev. B (accepted).

3. "Radio-Frequency Surface Impedance of Type-II Superconductors: Dependence Upon the Magnitude and Angle of an Applied Static Magnetic Fleld", John R. Clem and Mark W. Coffey, $M^{2}$ S-HTSC III: Proceedings of the Third International Conference on Materials and Mechanisms of Superconductivity - HighTemperature Superconductors, Kanazawa, Japan, July 22-26, 1991 (to be published as a Special Issue of Physica C), edited by M. Tachikd, Y. Muto, and Y. Syono. (accepted).

4. "Fundamentals of Vortices in the High-Temperature Superconductors", John R. Clem. Proceedings of the 6th International Workshop on Critical Currents), July 8-11, 1991. Churchill College, Cambridge, England (accepted).

5. "A Scaling Property in the Reversible Magnetization of Anisotropic High-k TypeII Superconductors", Zhidong Hao, John R. Clem, J.H. Cho and D.C. Johnston, $\mathrm{M}^{2} \mathrm{~S}-\mathrm{HTSC}$ III: Proceedings of the Third International Conference on Materials and Mechanisms of Superconductivity - High-Temperature Superconductors, Kanazawa, Japan, July 22-26, 1991 (to be published as a Special Issue of Physica C), edited by M. Tachikd, Y. Muto, and Y. Syono. (accepted).

6. "Flux Pinning and Critical Currents in Superconductor-Normal Metal Composites", D. K. Finnemore, Ming Xu, Qlang LI and J. E. Ostenson, Advances in Science (accepted).

7. "Synthesis and Characterization of Ceramic $\left(\mathrm{SR}_{1-\mathrm{x}} \mathrm{Cax}\right)_{2} \mathrm{CuO}_{3}$ ", M. Xu, E. T. Volles, L. S. Chumbley, A. I. Goldman, and D. K. Finnemore, (accepted to J. Mat. Res., (1991).

8. "Melting and Freezing of Bi-Sr-Ca-Cu-O Compounds", J. Polonka, Ming Xu, A.I. Goldman, D.K. Finnemore and Qlang Ll, (Accepted, Superconductor Science and Technology).

9. "Inttial Magnetization and Magnetic Relaxation in a Single Crystal of $\mathrm{Bi}_{2} \mathrm{Sr}_{2} \mathrm{CaCu}_{2} \mathrm{O}_{\mathrm{x}}$. Ming Xu, A. Umazawa and G.W. Crabtree, to be Published in Physica C. (Goldman, Finnemore, Chumbley Group)

10. "Magnetic Relaxation in Generalized Critical State Model", Ming Xu, to be Published in Physica C. (Goldman, Finnemore, Chumbley Group)

11. "Phase-Slip Resistivity in High Temperature Superconductors: a Manifestation of Intrinsic Nano-Granularity", H. A. Blackstead, to be published in Journal of Superconductivity. 
12. "Microwave Mixing in and SQUID performance of TlBaCaCuOx Thin-Film Structures", S.T. Rugglero, M.W. McElfresh, A.H. Cardona, L.C. Bourne, H.R. Fetterman, (Accepted for the International Materials and Mechanisms of Superconductivity (High-Temperature Superconductors) Conference, Kanazawa, Japan, (1991).

13. "Microstructure and Critical Current Density of Zone Melt Textured $\mathrm{YBa}_{2} \mathrm{Cu}_{3} \mathrm{O}_{6}+\mathrm{x}$ with $\mathrm{Y}_{2} \mathrm{BaCuO}_{5}$ Additions", P. McGinn, W. Chen, N. Zhu, S. Sengupta, T. Li, High Temperature Superconducting Compounds III, ed. by S. H. Whang, A. DasGupta, E. Collings, 129-140, (1991).

14. "Molecular Beam Deposition of $\mathrm{Dy}_{1} \mathrm{Ba}_{2} \mathrm{Cu}_{3} \mathrm{O}_{7-\delta}$ (001) High Temperature Superconductor Thin Films", J. Bae, P. Seshadrl and K.M. Choudhary, accepted to J. Vac. Sci. \& Tech. A.

15. "Critical Currents of Composite Superconductors: Model Calculations", K. H. Lee and D. Stroud, (Accepted to Phys. Rev, B.).

16. "Structural Developments in the Bi-Sr-Ca-Cu-O Superconductors from Amorphous Precursors", N. Ohnish1, M. Sankararaman, Z. P. Zhang, H. Zhang, and $\mathbf{H}$. Sato, High Temperature Superconducting Compounds III: edited by S. H. Whang, A. Das Gupta and E. Collings, TMS (1991) pp. 209-204. 


\title{
PUBLICATIONS - SUBMITTED FOR PUBLICATION
}

\author{
(Preprints Available On Request)
}

1. "Landau Quantization and Particle-Particle Ladder Sums in a Magnetic Field", A. H. MacDonald, H. Akera and M. R. Norman, (submitted to Phys. Rev. B).

2. "Theory of $\mathrm{rf}$ Magnetic Permeabllity of Isotropic Type-II Superconductors in a Parallel Field", M. W. Coffey and J. R. Clem, Phys. Rev. B (submitted).

3. "Theory of if Magnetic Permeabllity of Type-II Superconductors in Slab Geometry with Oblique Applied Static Magnetic Field", M. W. Coffey and J. R. Clem, Phys. Rev. B (submitted).

4. "Fraunhofer Oscillations in a Multilayer System with Josephson Coupling of Layers", L. N. Bulaevskd1, J. R. Clem, and L. I. Glazman, Phys. Rev. B (submitted).

5. "Angular Dependences of the Thermodynamic and Electromagnetic Properties of the High- $T_{C}$ Superconductors in the Mixed State", Z. Hao and J. R. Clem, Phys. Rev. Lett. (submitted).

6. "Melting of the Abrikosov Flux Lattice in Anisotropic Superconductors", R. G. Beck, D. E. Farrell, J. F. Rice, D. M. Ginsberg, and v. G. Kogan, Phys. Rev. Lett. (submitted).

7. "Magnetic Properties of Layered Superconductors Near $\mathrm{H}_{\mathrm{C} 2}$, , Z. Hao, Phys. Rev, B (submitted) (Clem, Kogan Group).

8. "The Spectrum of Quasiparticles in S-N Superlattices", L.N. Bulaevskil and R. Rammal. (Clem, Kogan Group)( submitted for publication).

9. "Vortices in Layered Superconductors with Josephson Coupling", L. N. Bulaevskil, M. Ledvij, and V. G. Kogan, (submitted).

10. "Crystalline Phases Durng the Melting $\mathrm{Bi}_{2} \mathrm{Sr}_{2} \mathrm{CaCu}_{2} \mathrm{O}_{\mathrm{x}}$, Ming Xu, J. Polonka, A. I. Goldman, D. K. Finnemore, $\mathrm{Q}$. Li and F. C. Laabs, (submitted J. Mat. Res).

11. "Containerless Melt Processing of $\mathrm{REBa} 2 \mathrm{Cu}_{3} \mathrm{O}_{7-\mathrm{x}}\{\mathrm{RE}=\mathrm{Y}, \mathrm{Gd}, \mathrm{Nd}\} \mathrm{High}$ Temperature Superconductor", R. W. McCallum, M. J. Kramer, T. J. Folkerts, S. R. Arrasmith, B. D. Merkle, S. I. Yoo, Youwen Xu, and K. W. Dennis, (submitted for publication).

12. "Field Induced Resistivity in Crystalline $\mathrm{YBa}_{2} \mathrm{Cu}_{3} \mathrm{O}_{7-\delta}$ : Evidence for Granularity", H. A. Blackstead, D. G. Keiffer, M. D. Lan, and J. Z. Liu (submitted for publication).

13. "Flux-Flow and Phase-Slip Resistivity in Two Phase Polycrystalline $\mathrm{B1}_{1.6} \mathrm{~Pb} 0.4 \mathrm{Sr}_{1.7} \mathrm{Ca}_{2} \mathrm{Cu}_{3} \mathrm{O}_{\mathrm{x}}$, H.A. Blackstead, D.B. Pulling and H. Sato, (submitted for publication).

14. "Current Density Dependence of the Activation Energy in Type II Superconductors", S. Sengupta, D. Shi, S. Salem-Sugui, Z. Wang, P. McGinn, K. DeMoranville, (submitted to Appl. Phys. Lett., October 1991).

15. "Interactions Between $\mathrm{YBa}_{2} \mathrm{Cu}_{3} \mathrm{O}_{6+\mathrm{x}}$ and $\mathrm{BaSnO}_{3}$ During Melt Texturing", $\mathbf{P}$. McGinn, C. Varanasi, D. Balkin (submitted to Physica C, November 1991). 
16. "A TEM Study of Grain Boundaries in Zone Melted YBa2 $\mathrm{Cu}_{3} \mathrm{O}_{\mathrm{x}}$ ", J.G. Chen, D. Shi, C.M. Wayman, P.J. McGinn, W. Chen, N. Zhu, (Submitted to Applied Physics Letters, Feb., 1991).

17. "Epitaxial Growth of $\mathrm{Dy}_{1} \mathrm{Ba}_{2} \mathrm{Cu}_{3} \mathrm{O}_{7-\delta}(001)$ High Temperature Superconductor Thin Films by Molecular Beam Deposition using BaF 2 Technique", K.M. Choudhary, J. Bae, and P. Seshadri, submitted to Jpn. J. Appl. Phys. (Lett.).

18. "Molecular Beam Epitaxy of $\mathrm{Dy}_{1} \mathrm{Ba}_{2} \mathrm{Cu}_{3} \mathrm{O}_{7-\delta}(001)$ Thin Films Using $\mathrm{BaF}_{2}$ Technique", K.M. Choudhary, J. Bae, P. Seshadrl and S.T. Rugglero, submitted to Appl. Phys. Letts. (June 1991).

19. "Epitaxial Growth of $\mathrm{Dy}_{1} \mathrm{Ba}_{2} \mathrm{Cu}_{3} \mathrm{O}_{7-\delta}(001)$ and $\mathrm{Dy}_{1+\mathrm{x}} \mathrm{Ba}_{2-\mathrm{x}} \mathrm{Cu}_{3} \mathrm{O}_{\mathrm{y}}(001)$ Thin Films by Molecular Beam Epitaxy", K.M. Choudhary. J. Bae, P. Seshadri and S.T. Ruggiero, Abstract submitted to the 38th Annual Symposium of the American Vacuum Society, (Seattle, WA, Nov. 11-15, 1991).

20. "The Critical Current of $\mathrm{Ag} / \mathrm{YBa}_{2} \mathrm{Cu} \mathrm{O}_{7-\delta}$ Random Bulk Composites", J. J. Calabrese, M. A. Dubson, and J. C. Garland, (submitted to J. Appl. Physs) (1991).

21. "Metal-Insulator Transitions, Exchange Interactions and Real Space Pairing: An Introduction to the Theory of Strongly Correlated Electron Systems", J. Spalek, and J.M. Honig, (submitted to Studies of High Temperature Superconductors).

22. "Influence of Oxygen Non-Stoichiometry on the Antuferromagnetic Ordering of Single Crystals of La2N104+ $\delta$ ", P. Gopalan, M. McElfresh, Z. Kakol, J. Spalek, and J.M. Honig, Phys. Rev B. (1991).

23. "Effect of Flux Creep on the Temperature Dependence of the Current Density in YBaCuO Crystals", J. R. Thompson, Y. R. Sun, L. Civale, A. P. Malozemoff, M. W. McElfresh, A. D. Marwick, and F. Holtzberg, (submitted to Phys. Rev. B). 


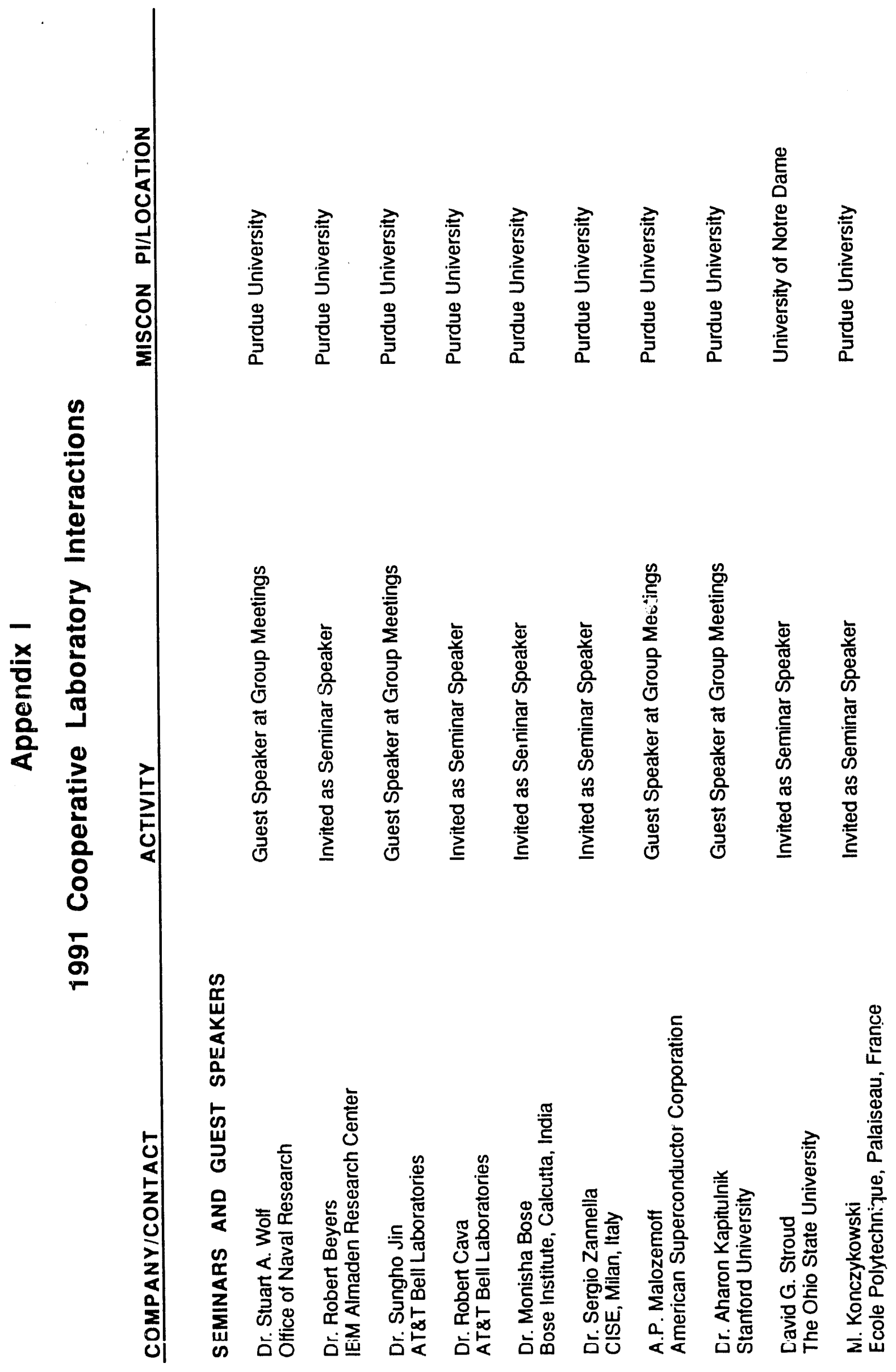




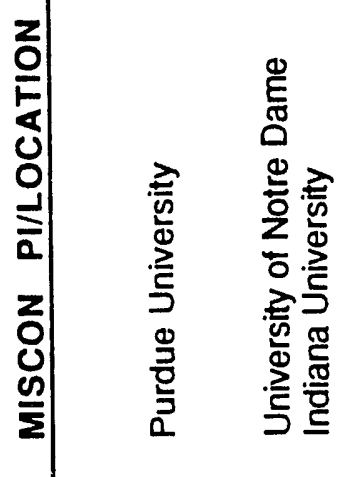

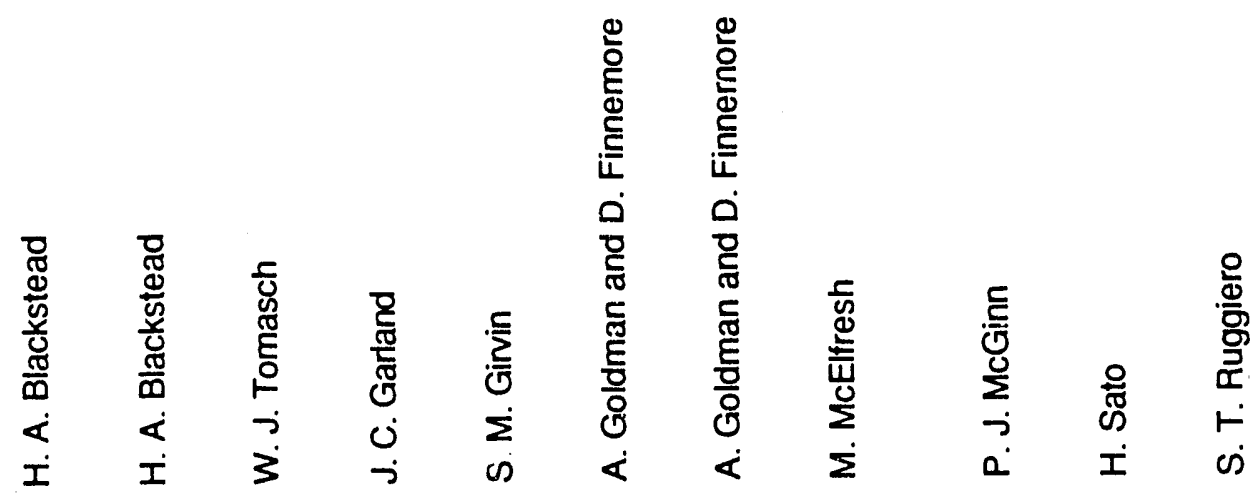

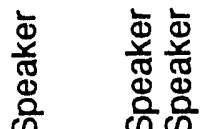

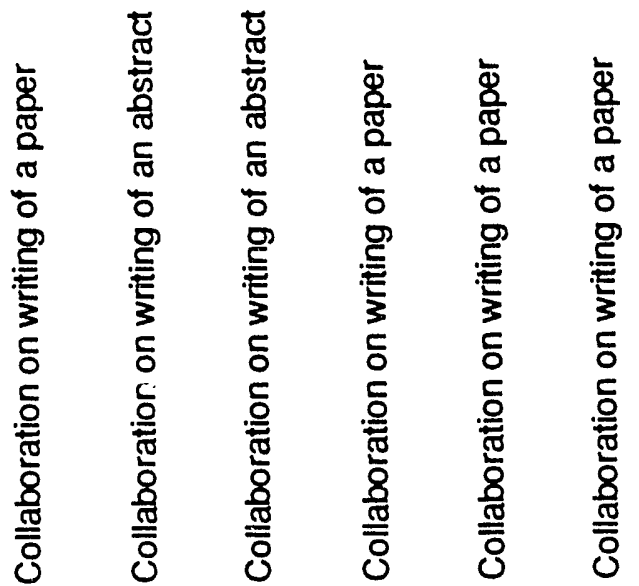

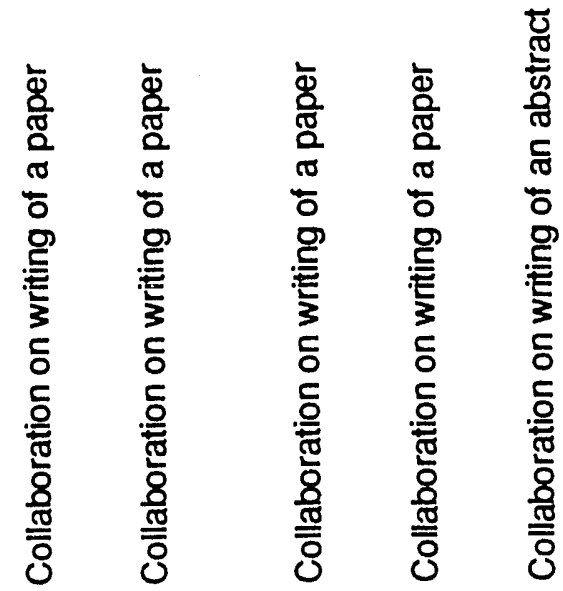

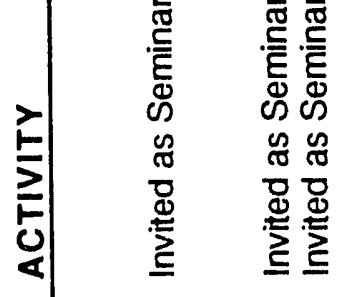

車

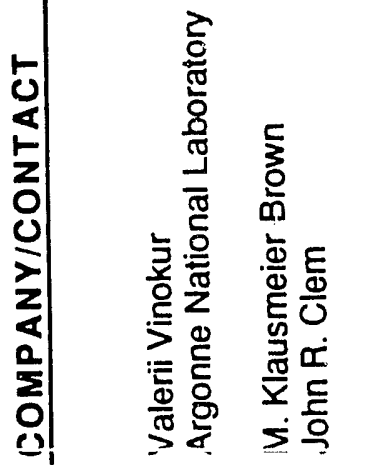

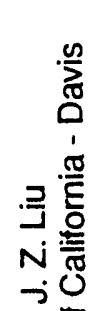

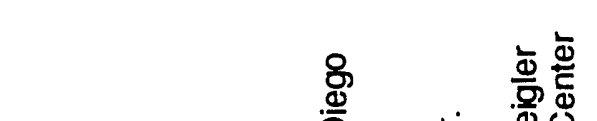

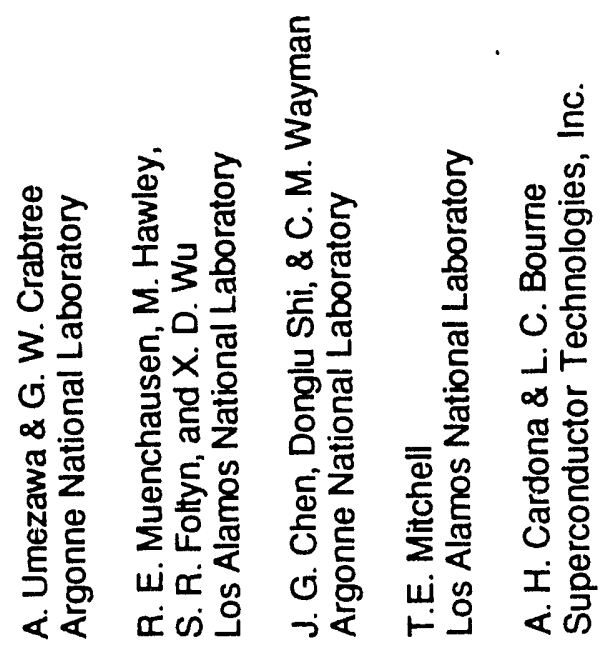



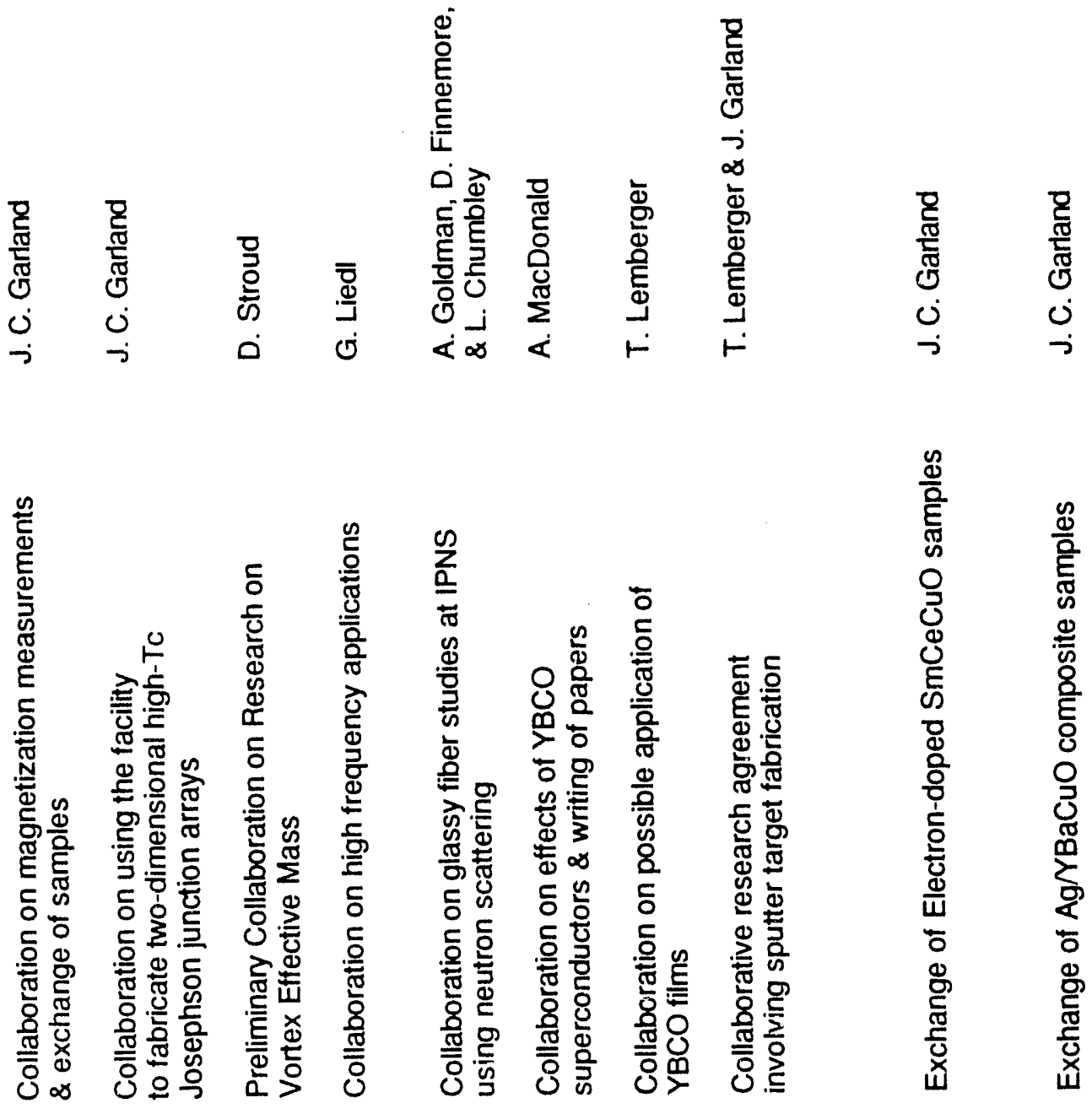

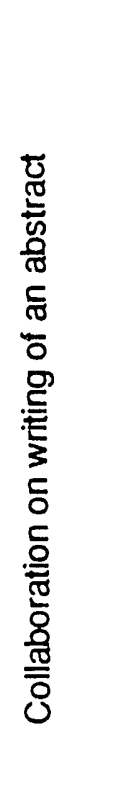

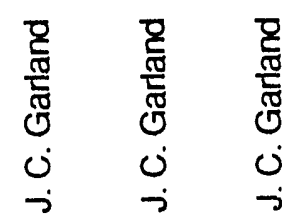

宽

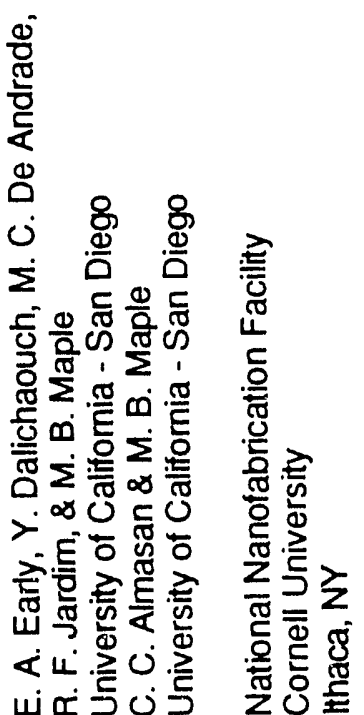
《山.
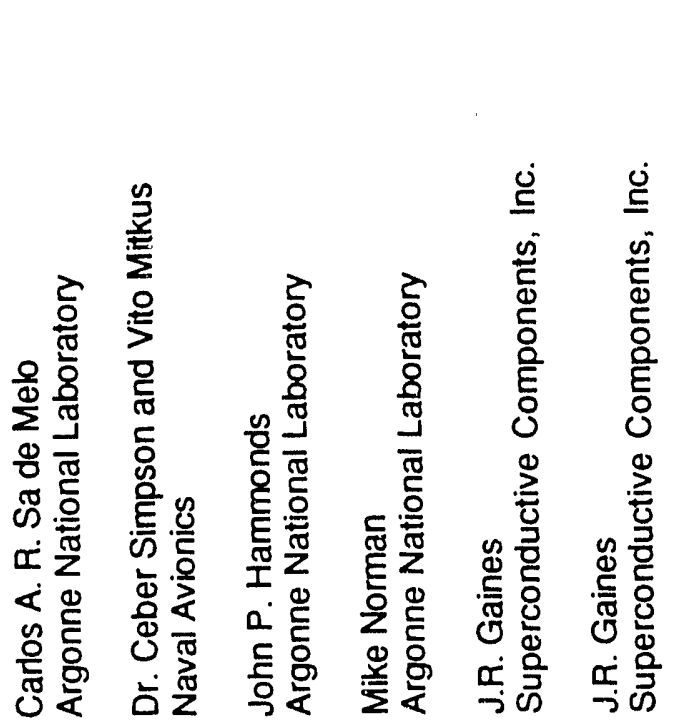


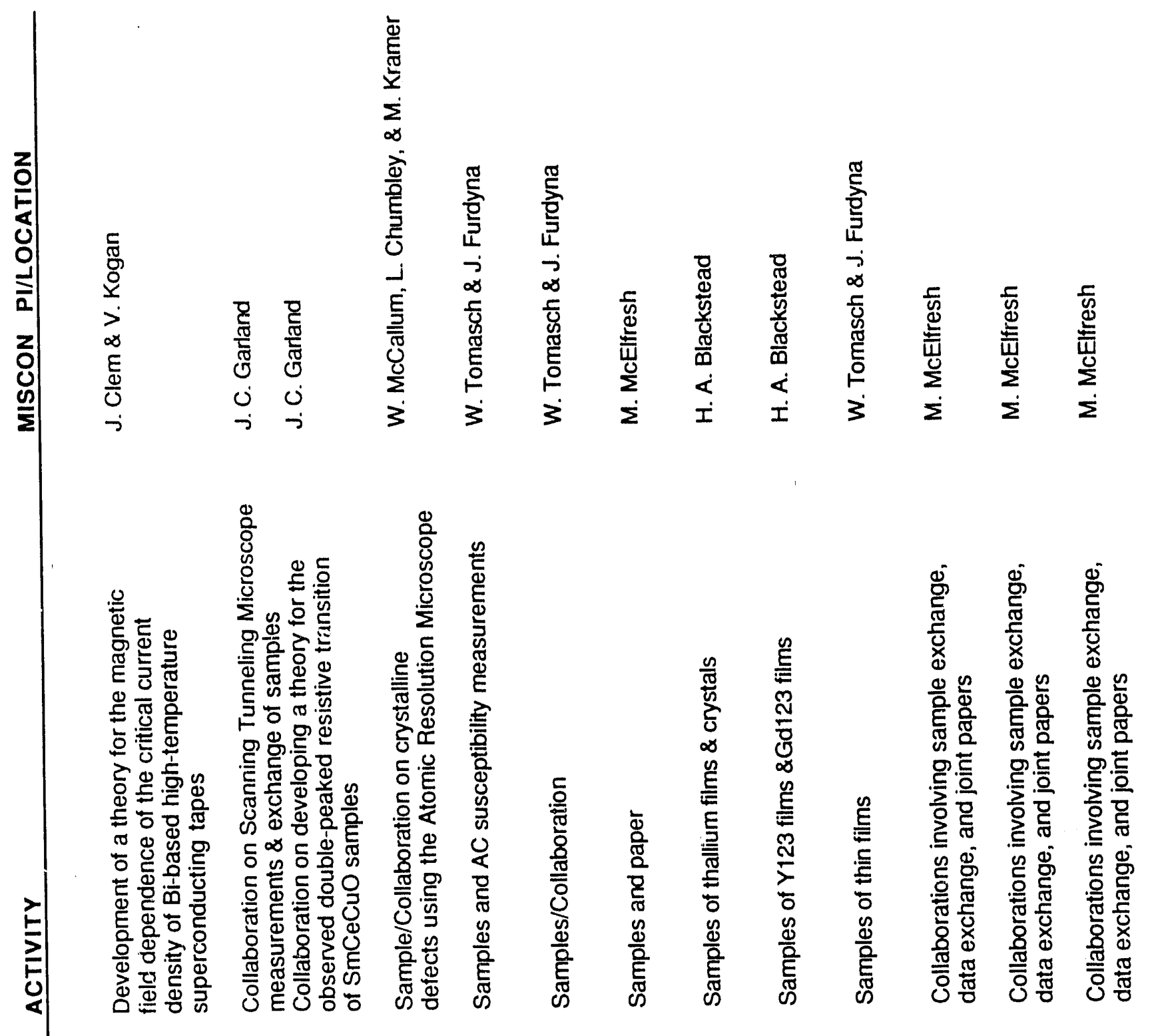

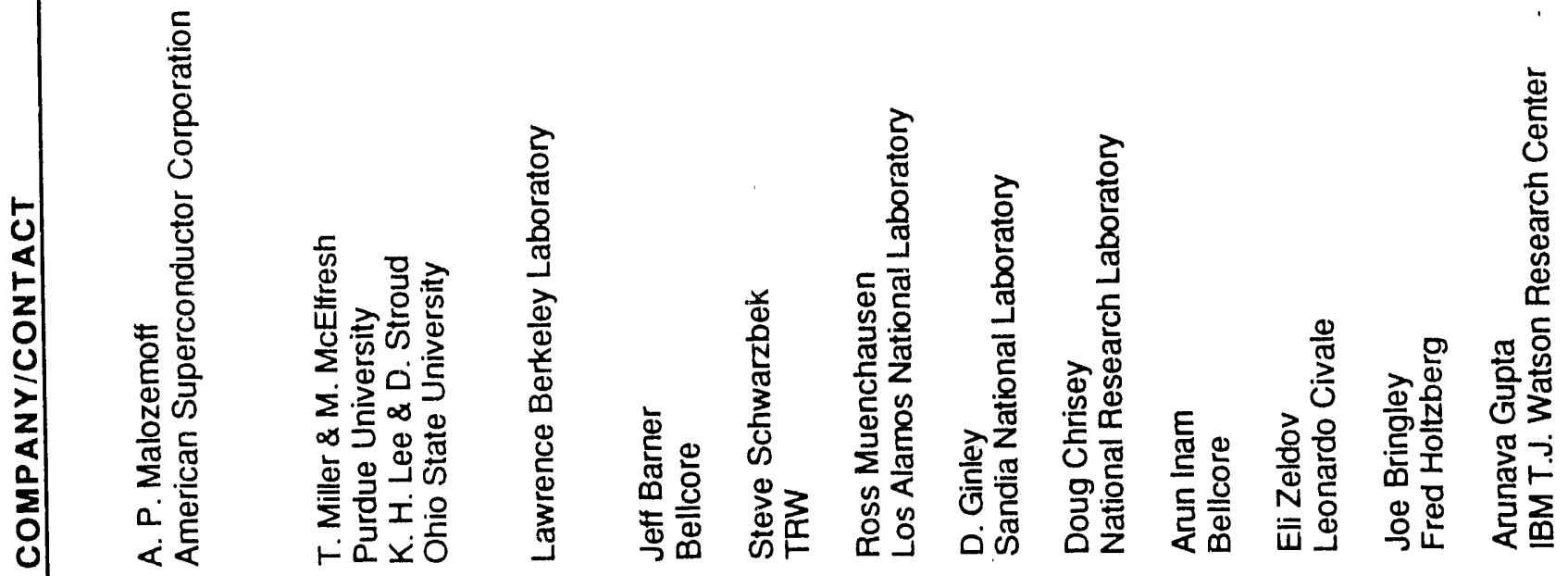




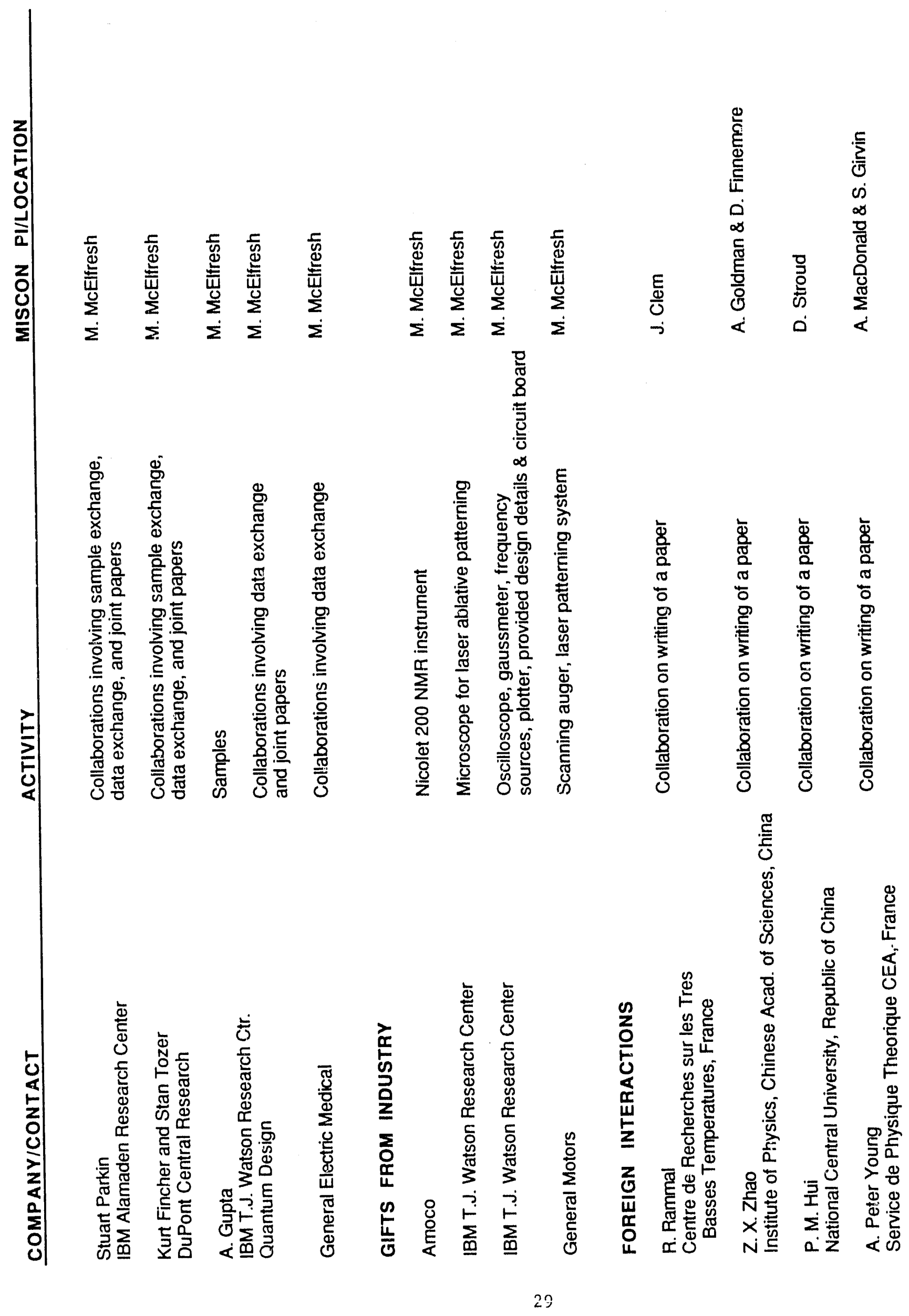




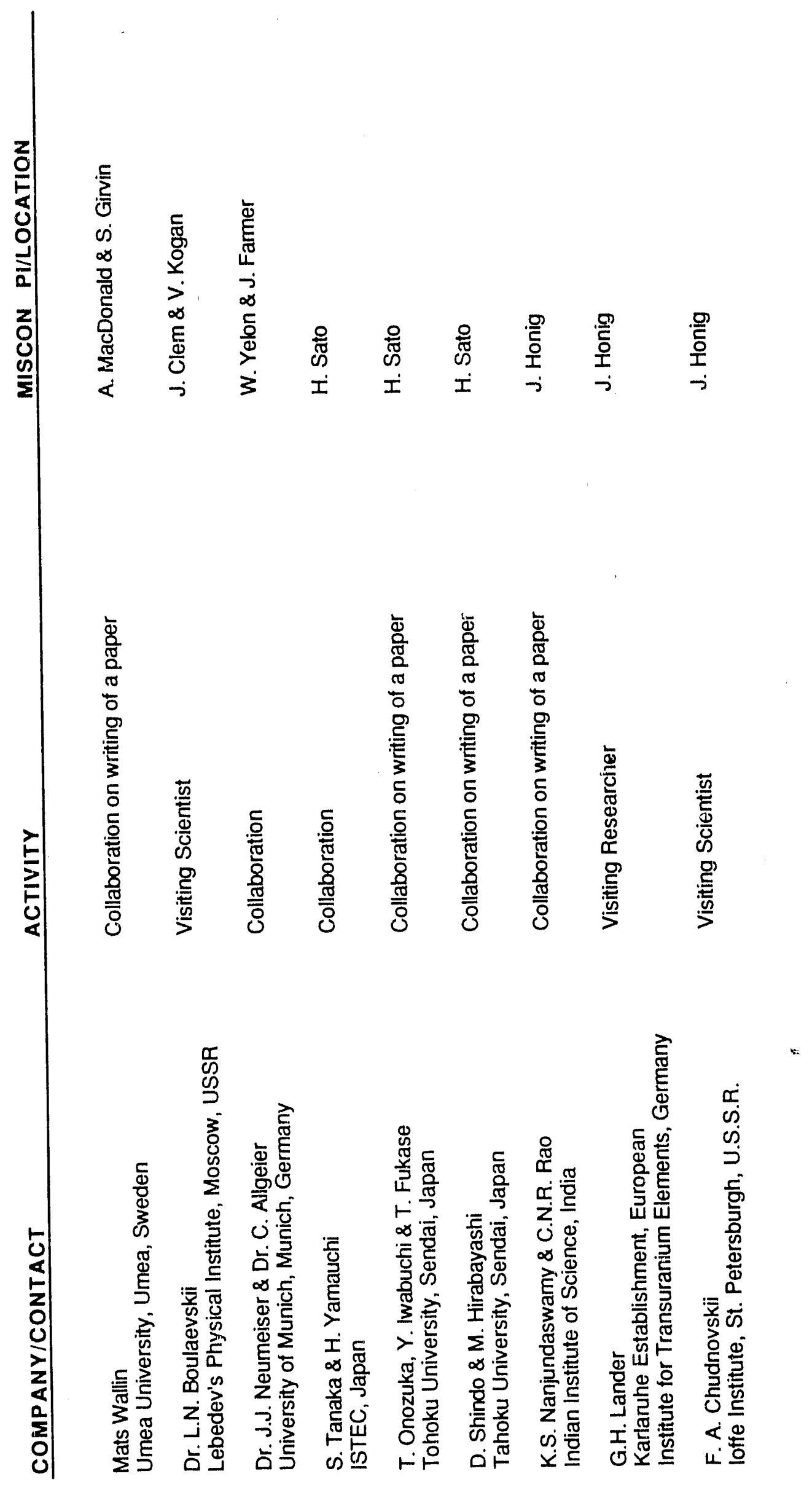



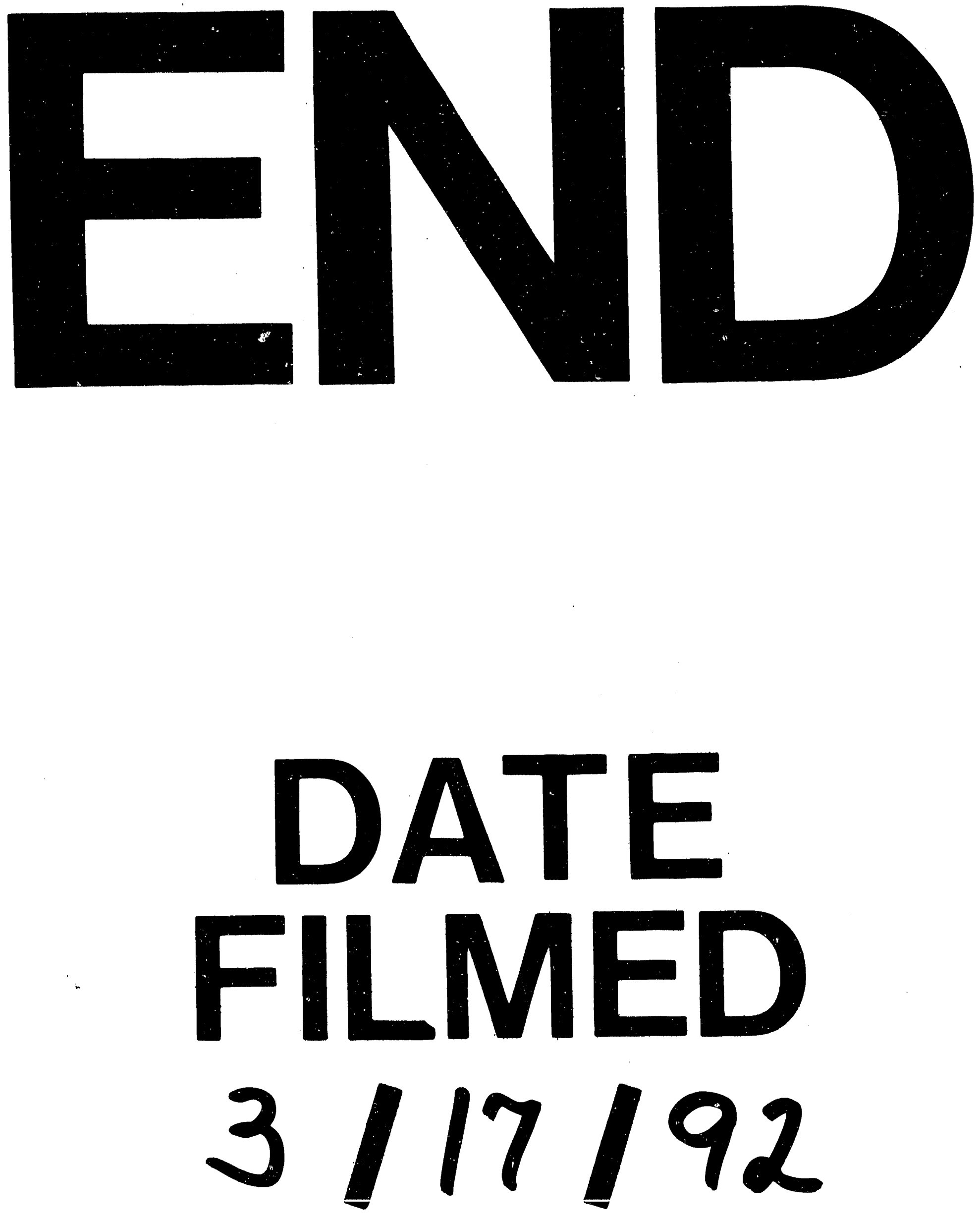
